\title{
Improvements in Machinability of Zinc Oxide Ceramics by Laser-Assisted Milling
}

\author{
David Muženič* - Jaka Dugar - Davorin Kramar - Matija Jezeršek - Franci Pušavec \\ University of Ljubljana, Faculty of Mechanical Engineering, Slovenia
}

In this paper, an attempt is made to advance the understanding of Laser-Assisted Milling (LAMill) of zinc oxide (ZnO) ceramics. A series of conventional milling and LAMill experiments with varying laser power were conducted to determine the effect of laser assistance on the machinability of this material. Improved machinability in terms of reduction in machined surface roughness and edge chipping was achieved by adjusting laser power. At an optimal laser power of $120 \mathrm{~W}$, determined for the machining parameters used, $R_{a}$ and $R_{z}$ were reduced by $37 \%$ and $46 \%$, respectively, while the average and maximum chipping widths were reduced by $15 \%$ and $17 \%$, respectively.

Keywords: zinc oxide ( $\mathrm{ZnO}$ ) ceramics, machinability, laser-assisted milling, surface roughness, edge chipping

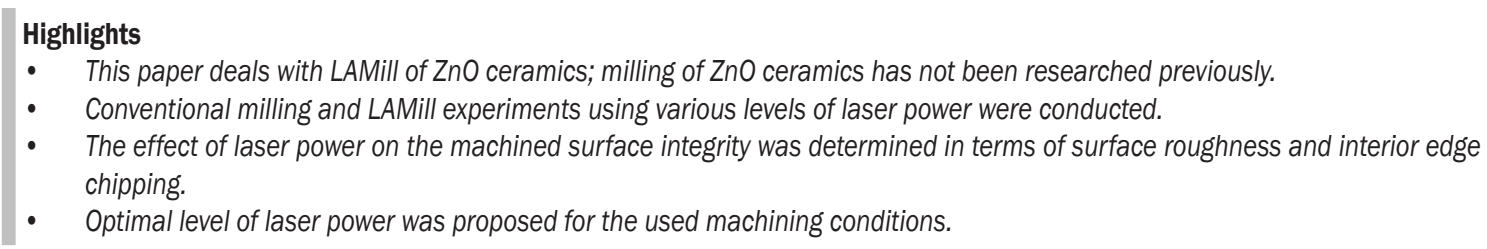

\section{INTRODUCTION}

Machinability in cutting processes, which is the ability to economically machine a certain material, is usually closely related to the performance of the tobe-cut material. Engineering ceramics are known for their poor machinability due to high hardness and brittleness. Thus, often the state-of-the-art in precision shaping of these materials are low material-removal rate processes, e.g. grinding and lapping, resulting in high machining costs. Nowadays, new ceramic materials are being developed in different areas of the industry (e.g. electronic ceramics). These ceramics are usually not known for high hardness or strength, yet high brittleness and low fracture toughness that lead towards excessive edge chipping. Therefore, machinability of these materials is significantly reduced. Edge chipping of ceramics is sudden edge damage on the macro- or microscale, caused by fractures usually while the cutting tool either comes in contact or separates from the workpiece. $\mathrm{Ng}$ et al. [1] described three types of edge chipping, namely entry edge chipping, interior edge chipping and exit edge chipping (Fig. 1), while milling a tetrasilicic mica glass ceramic. On finished parts, the presence of edge chipping is detrimental to the mechanical characteristics as well as dimensional and geometrical accuracy, and often severely limits the productivity of ceramic machining processes.

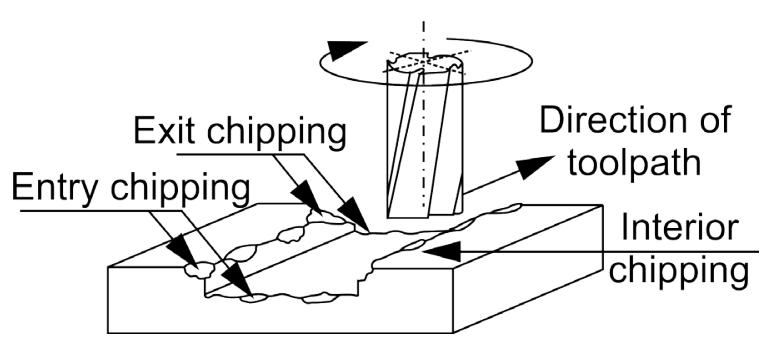

Fig. 1. Types of edge chipping [1]

Some improvements in machinability of both structural and electronic ceramics were achieved by optimizing the conventional fixed abrasive machining processes [2]. Besides improvements in conventional processes, large reductions in cutting forces and edge chipping in ceramics fixed abrasive machining were achieved with ultrasonic oscillations of the cutting tool during machining [3]. Another hybrid approach to fixed abrasive machining of silicon nitride $\left(\mathrm{Si}_{3} \mathrm{~N}_{4}\right)$ structural ceramics was presented by Guerrini et al. [4]. The authors proposed a combined process wherein a laser source is used to induce controlled cracking of the workpiece material surface, which aids the consequent grinding process. Zhang et al. [5] have adopted a similar shaping approach for zirconium oxide ceramics. Besides improvements in fixed abrasive machining processes, other non-traditional or hybrid processes such as electrical-discharge machining [6], laser machining [7] and thermally 
enhanced machining [8] have been used to address the poor machinability of ceramic materials.

In thermally enhanced machining, a heat source is used to heat the workpiece material right before the cutting zone, resulting in local softening of the to-be-cut material. By heating ceramic materials above a certain temperature, a reduction in hardness can be achieved as well as the change in deformation behaviour from brittle to ductile [9]. Amongst the thermally enhanced machining processes, laserassisted machining (LAM) has been shown to be superior method for improving the machinability of different structural ceramics due to the ability of a fast, local and controlled input of heat into the workpiece material. In comparison to grinding and lapping, much higher material-removal rates can be achieved in LAM, leading to a significant reduction in machining costs. Lei et al. [10] evaluated the potential of laser-assisted turning (LAT) as an economically viable process for the fabrication of precision $\mathrm{Si}_{3} \mathrm{~N}_{4}$ ceramic parts. Compared to the conventional diamond grinding, a decrease in the thickness of the subsurface damage layer was observed, while achieving tool life, comparable to metal cutting. Tian et al. [11] also report on achieving tool life, comparable to metal cutting, while successfully producing $\mathrm{Si}_{3} \mathrm{~N}_{4}$ parts with complex geometry. Pfefferkorn et al. [12] demonstrated the feasibility of LAT of magnesiapartially-stabilized zirconia (PSZ) by achieving a process with $0 \%$ flaws, which would cause a workpiece to be scrapped. The experiments showed that at a laser power of $100 \mathrm{~W}$, the material removal temperature rises to $530{ }^{\circ} \mathrm{C}$ and the material can be successfully machined, although a PCBN-tipped tool life was only $3 \mathrm{~min}$. Further increasing the laser power to $250 \mathrm{~W}$ leads to a material removal temperature of $1210{ }^{\circ} \mathrm{C}$ and a drastic increase in tool life (up to $120 \mathrm{~min}$ ). While several studies on LAT of structural ceramics are reported in literature, the authors found only two reports on laser-assisted milling (LAMill) of these materials. The possible reasons for that are that LAMill is generally more complex than LAT with regards to the laser setup and in the case of brittle materials, milling is significantly more subjected to workpiece edge chipping than turning. Tian et al. [13] achieved good surface finish, repeatable performance and acceptable tool wear in LAMill of $\mathrm{Si}_{3} \mathrm{~N}_{4}$ ceramics using TiAlN coated carbide tools, although the problem of edge chipping was not addressed in this study. A detailed study on edge chipping mechanisms in LAMill of this material was presented by Yang et al. [9]. The authors concluded that by heating the material above the softening point, edge chipping is reduced due to the reduction in cutting forces. By heating the material further, above the brittle/ductile transition temperature, edge toughness of $\mathrm{Si}_{3} \mathrm{~N}_{4}$ is increased significantly, resulting in a further reduction of edge chipping.

In this study, an attempt is made to advance the understanding of LAMill on the machinability of zinc oxide $(\mathrm{ZnO})$ based ceramic. Detailed information about the composition and preparation of those ceramics are provided in [14]. Lapping process represents the state of the art in machining of $\mathrm{ZnO}$ ceramic. Achieving a successful milling operation, however, would result in a drastic increase in quality, achievable material removal rate and consequently a decrease in machining costs. No reports on machining of this material can be found in literature, nor information about the material edge toughness or edge chipping tendencies. The authors performed preliminary studies on conventional milling of $\mathrm{ZnO}$ ceramics and concluded that conventional milling is not appropriate for its machining and that edge chipping is the main factor, reducing its machinability. The latter is supported by comparing the fracture toughness of zinc oxide ceramics $\left(2.10 \mathrm{MPa} \cdot \mathrm{m}^{1 / 2}\right.$ to $2.16 \mathrm{MPa} \cdot \mathrm{m}^{1 / 2}$ [15]) to previously discussed structural ceramics (for example $\mathrm{Si}_{3} \mathrm{~N}_{4}, 4 \mathrm{MPa} \cdot \mathrm{m}^{1 / 2}$ to $\left.8 \mathrm{MPa} \cdot \mathrm{m}^{1 / 2}[16]\right)$.

Based on the similarities between $\mathrm{ZnO}$ ceramics and other electronic ceramics, or even structural ceramics, the authors assume that laser assistance should provide significant machinability improvement in milling of $\mathrm{ZnO}$ ceramic material. Therefore, the aim of this study is defining the effect of laser assistance on the machinability of zinc oxide ceramics. To observe laser assistance significance, only laser power was varied throughout the experimental repetitions, while the machining parameters were kept constant at levels that were found as optimal by the preliminary conventional milling experiments.

\section{EXPERIMENTAL PROCEDURE}

\subsection{Laser-Assisted Milling Experiments}

The laser-assisted dry milling experiments were performed on a 3-axis Mori Seiki Frontier M1 vertical machining center, equipped with a $400 \mathrm{~W}$ YLR-400AC continuous wave fiber laser from IPG Photonics with a wavelength of $1070 \mathrm{~nm}$ and the collimated laser beam diameter of $5 \mathrm{~mm}$. The cutting tool used in the experiments was a DIXI 72420 PCD end mill with a diameter of $4 \mathrm{~mm}$ and a single cutting edge. 
A depth and width of cut of $0.1 \mathrm{~mm}$ and $0.33 \mathrm{~mm}$, respectively, a feed velocity of 250 $\mathrm{mm} / \mathrm{min}$, a spindle speed of $6250 \mathrm{rev} / \mathrm{min}$ $\left(v_{\mathrm{c}}=78.5 \mathrm{~m} / \mathrm{min}\right.$ and $\left.f_{\mathrm{z}}=0.04 \mathrm{~mm}\right)$ and the position of the laser spot relative to the cutting tool (Fig. 2) were kept constant throughout all experimental repetitions. For every experimental repetition, a $4 \mathrm{~mm}$ wide and $0.1 \mathrm{~mm}$ deep slot was milled at the centre of the workpiece in the $x$-direction without laser assistance and then two consecutive LAMill passes with the same width of cut in the positive $y$-direction were performed, as shown in Fig. 2.

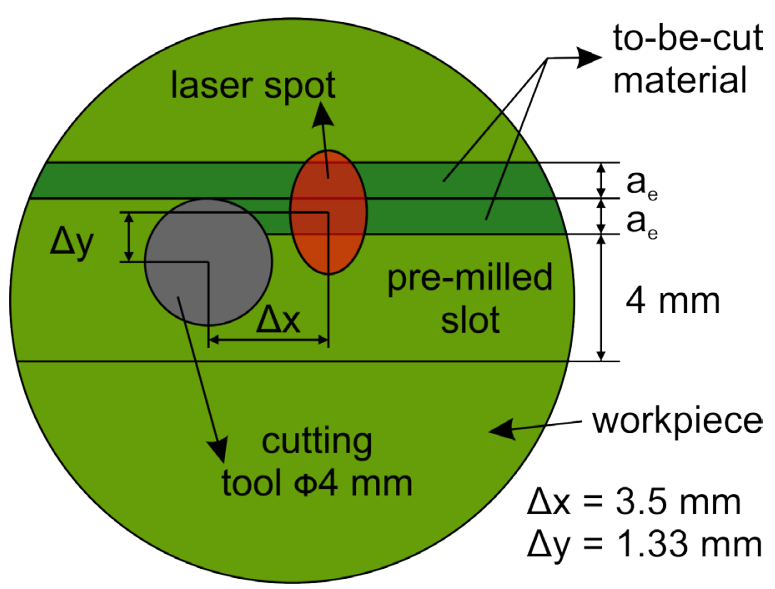

Fig. 2. Laser-assisted milling strategy

Table 1 shows the plan of laser-assisted milling experiments. Experiments $\mathrm{N}^{\circ} 1$ to 6 were performed with two repetitions with the same experimental parameters, each time on a new workpiece. As the results indicated an area of interest between the two used levels of laser power, four more experiments $\left(\mathrm{N}^{\circ}\right.$ 7 to 10) were performed, with one repetition per laser power used.

\subsection{Surface Integrity Analysis}

Surface integrity was evaluated in terms of interior edge chipping and machined surface roughness. For the purpose of surface integrity analysis, a 3D scan including the edge and the surface, generated in the two machining passes, shown in Fig. 2, was executed on an Alicona InfiniteFocusSL measurement system.
The measurement setup used for surface integrity analysis is shown in Fig. 3.

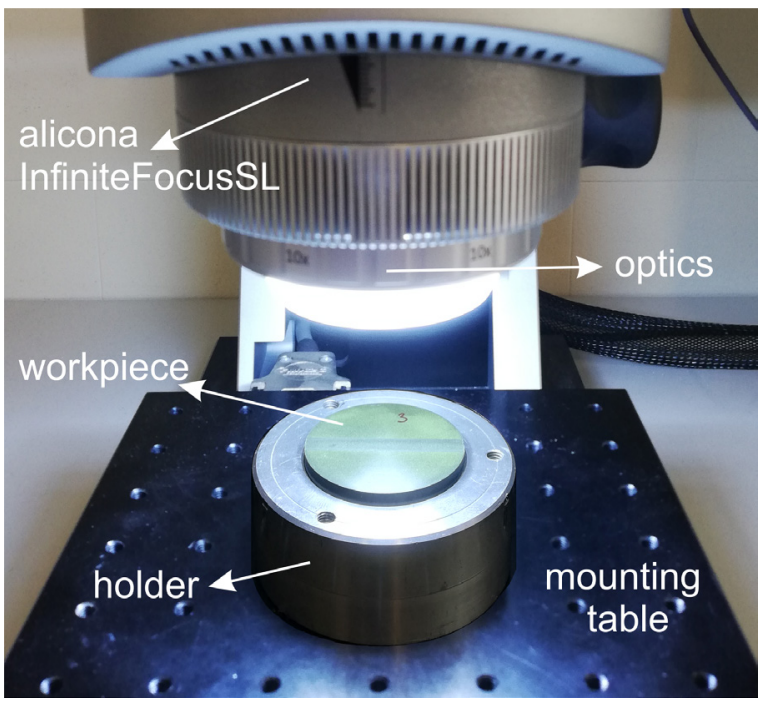

Fig. 3. Surface integrity measurement setup

Edge chipping was evaluated by fitting a reference plane on the portion of un-machined surface in the scan and extracting the intersection curve of a plane $5 \mu \mathrm{m}$ below the reference plane and the scanned surface. A plot of the distance from the reference plane for the case $0 \mathrm{~W}_{1}$, where the lower limit of the colour scale was set to $-5 \mu \mathrm{m}$ and thus evidencing the detected edge as the border of the black-coloured area is shown in Fig. 4a). A portion of the detected edge around the maximum detected chipping for the case $0 \mathrm{~W}_{1}$ is shown in Fig. 4b). Edge chipping is characterized by the chipping widths, $w_{\mathrm{c}, \mathrm{n}}$, which are the normal distances from the ideal edge, without edge defects (green line), to the local extremes (red marks) of the detected edge (blue line), as shown in Fig. 4 b). Two parameters were chosen to evaluate edge chipping, namely maximum $\left(w_{\mathrm{c}, \max }\right)$ and average $\left(w_{\mathrm{c}, \text { avg }}\right)$ chipping width, which are the maximum and mean value of the detected chipping widths in an experimental repetition, respectively.

Surface roughness at the machined surface (black area in Fig. 4a) was measured on three different randomly selected $5 \mathrm{~mm}$ long profiles in the $x$-direction for every experimental repetition. For each profile an average of 5 profiles, each $10 \mu \mathrm{m}$

Table 1. Plan of laser-assisted milling experiments

\begin{tabular}{lcccccccccc}
\hline $\mathrm{N}^{\circ}$ & 1 & 2 & 3 & 4 & 5 & 6 & 7 & 8 & 9 & 10 \\
\hline $\mathrm{P}[\mathrm{W}]$ & 0 & 0 & 80 & 80 & 160 & 160 & 110 & 120 & 130 & 140 \\
\hline label & $\mathrm{OW}_{1}$ & $\mathrm{OW}_{2}$ & $80 \mathrm{~W}_{1}$ & $80 \mathrm{~W}_{2}$ & $160 \mathrm{~W}_{1}$ & $160 \mathrm{~W}_{2}$ & $110 \mathrm{~W}_{1}$ & $120 \mathrm{~W}_{1}$ & $130 \mathrm{~W}_{1}$ & $140 \mathrm{~W}_{1}$ \\
\hline
\end{tabular}


a)

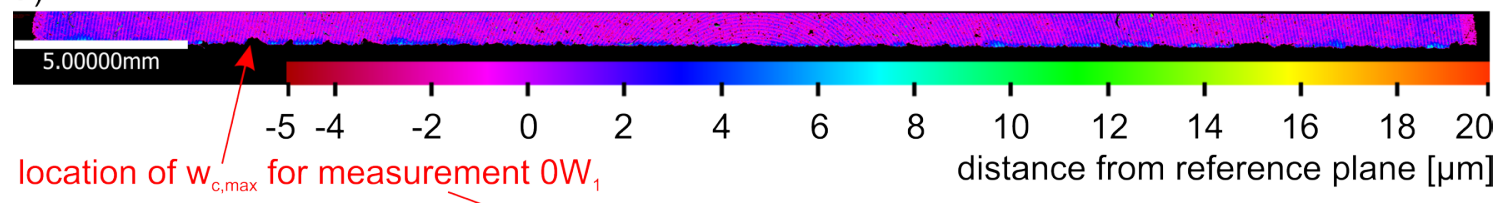

b)

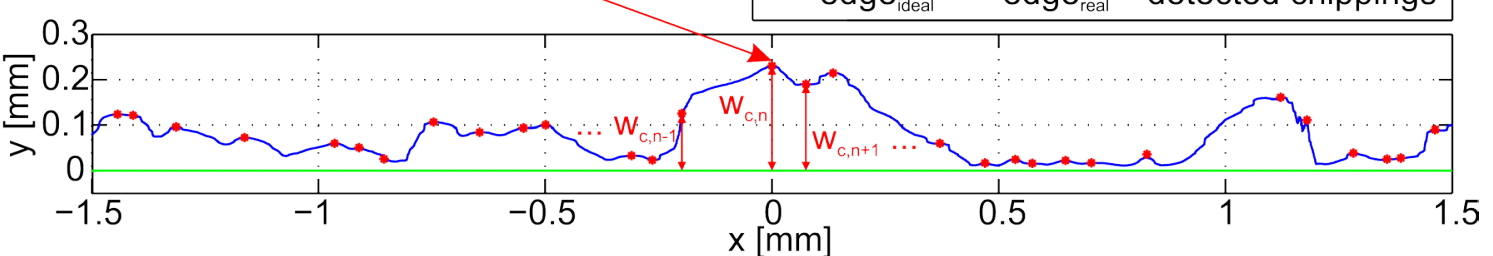

Fig. 4. Edge chipping: a) detection methodology and b) definition

apart in the $y$-direction, was taken into account and a cut-off wavelength of $800 \mu \mathrm{m}$ was used to eliminate waviness.

\section{RESULTS AND DISCUSSION}

The effects of laser power on the surface integrity of milled $\mathrm{ZnO}$ ceramic parts was evaluated in terms of machined surface roughness (chapter 2.1) and interior edge chipping (chapter 2.2). Furthermore, optimal level of laser power is discussed in chapter 2.3.

\subsection{Surface Roughness}

To evaluate the machined surface roughness, $R_{\mathrm{a}}$ and $R_{\mathrm{z}}$ were chosen as representative parameters. Fig. 5 shows the results of surface roughness measurements, grouped by the laser power used. Each vertical bar represents the highest and lowest measured value, while the connecting line represents the mean value for each group of experiments. Note that for laser powers of $0 \mathrm{~W}, 80 \mathrm{~W}$ and $160 \mathrm{~W}$, six measurements are included in the group, while only three measurements are included in the other groups.

The results are showing that both $R_{\mathrm{a}}$ and $R_{\mathrm{z}}$ decrease with laser power almost linearly from $0 \mathrm{~W}$ to $110 \mathrm{~W}$, followed by a sharp decrease at $120 \mathrm{~W}$ and a slight increase with further increasing the laser power. This suggests that $120 \mathrm{~W}$ is the optimal laser power level when milling $\mathrm{ZnO}$ ceramics with the proposed machining parameters. Furthermore, the difference between the highest and lowest measured $R_{\mathrm{a}}$ or $R_{\mathrm{z}}$, for a fixed laser power, decreases drastically when increasing the laser power above $80 \mathrm{~W}$. This suggests an improvement in process stability while increasing the laser power above a threshold value between $80 \mathrm{~W}$ and $110 \mathrm{~W}$.

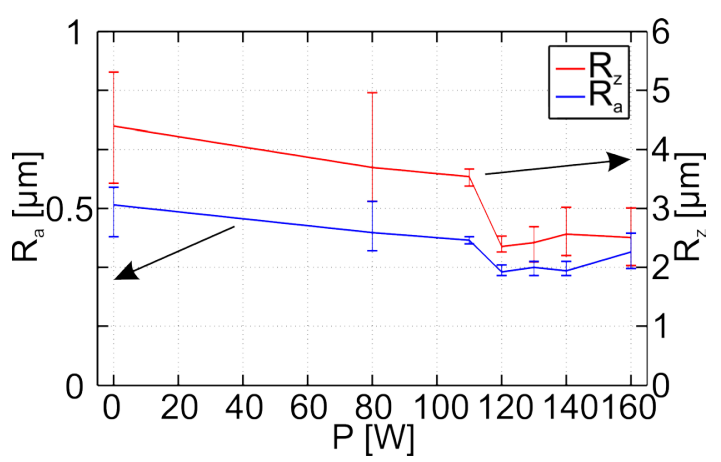

Fig. 5. Effect of laser power on machined surface roughness

The results are indicating that machined surface roughness is in direct correlation with the occurrence of grain pull-out during machining. The latter is facilitated by the brittleness of the thin layer of Birich intergranular phase, through which the cracks propagate during brittle fracture of this material at room temperature. By preheating the workpiece material before cutting, the intergranular phase softens, inhibiting grain pull-out. Furthermore, the authors assume that at a threshold value of laser power between $80 \mathrm{~W}$ and $110 \mathrm{~W}$, the material is heated above the glassy transition temperature of the Birich intergranular phase $\left(\sim 350{ }^{\circ} \mathrm{C}\right.$ [17]), resulting in changes in the deformation behaviour and the material removal mechanism. A brittle/ductile transition, like in the case of $\mathrm{Si}_{3} \mathrm{~N}_{4}$ [9], where random cracks during brittle fracture are replaced by the viscous flow of the workpiece material, would explain the increase in process stability. This means that, optimally, the laser power should be kept just above that point $(120 \mathrm{~W})$, 

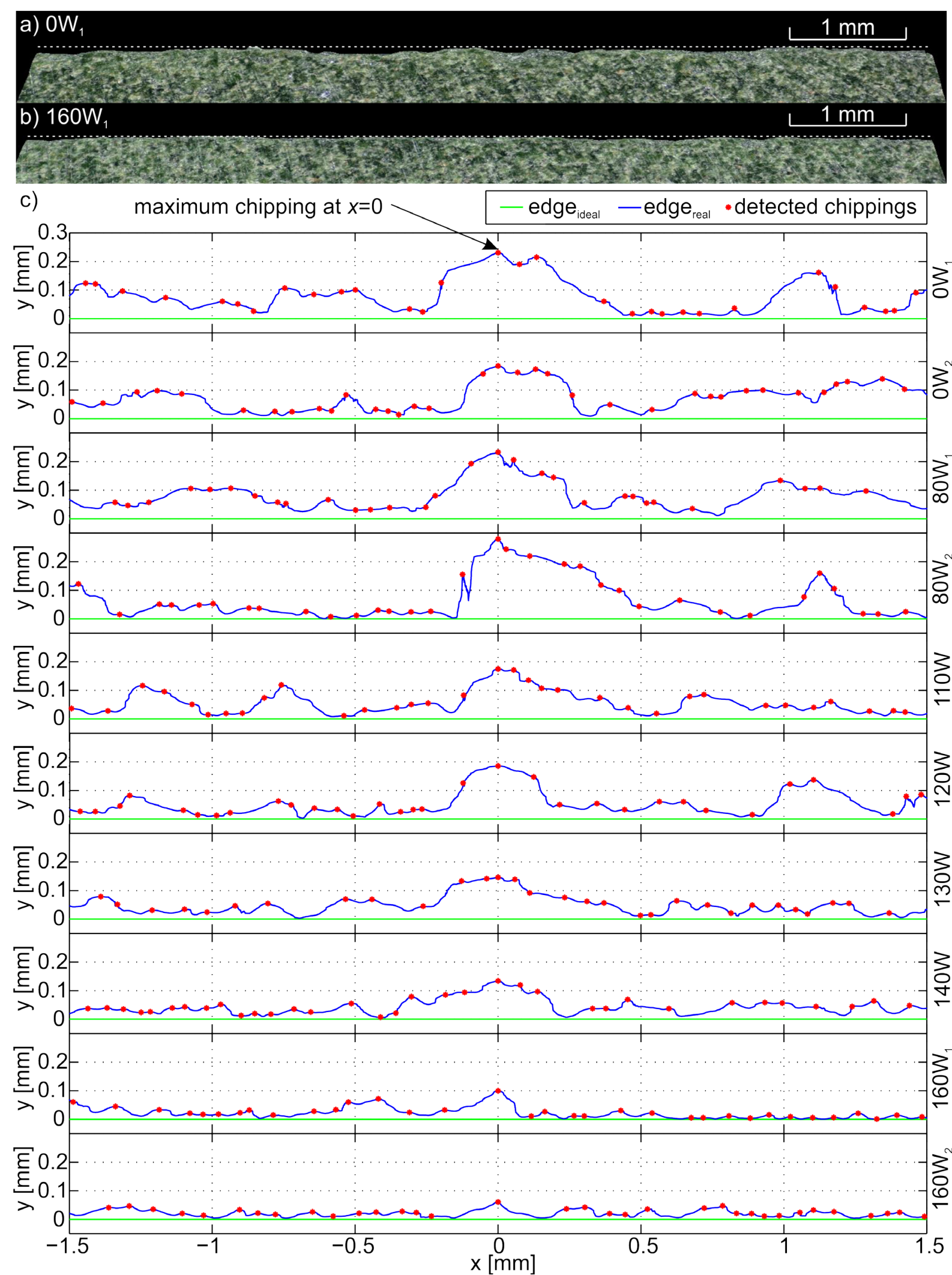

Fig. 6. Sample edge, achieved with a) conventional milling and b) LAMill using a laser power of $160 \mathrm{~W}$ and c) area around the maximum detected edge chipping for every experimental repetition 
as using higher power does not lead to improvements in surface roughness and results in cracks on the machined surface (Fig. 8).

\subsection{Edge Chipping}

Laser assistance has also a significant effect on interior edge chipping; however, its correlation with laser power differs from the findings of surface roughness. A sample edge, achieved with conventional milling in $0 \mathrm{~W}_{1}$ and a sample edge from $160 \mathrm{~W}_{1}$, where the best results regarding edge chipping were achieved, are presented in Fig. 6a) and b), respectively. Fig. 6 c) shows the area around $w_{\mathrm{c}, \max }$ (centred at $x=0$ ) for every experimental repetition and the detected chippings. It can be seen that the definition of a chipping differs from the literature [9] and [18]. To clarify, in this work, a chipping detection algorithm based on local extremes was constructed and used. In contrast with the other definitions of a chipping, several detected chippings in the area of a single, longer (in the $x$-direction) chipping are detected. However, as stated by Yang et al. [9], the maximum chipping width and the chipping area, which is the area surrounded by the real and ideal edges in Fig. 4, are independent of the chipping definition. Moreover, as the plot of chipping area shows the same trend as the $w_{\mathrm{c} \text {,avg }}$ in Fig. 7, the authors consider the algorithm to be appropriate for edge chipping evaluation. The dependence of $w_{\mathrm{c}, \max }$ and $w_{\mathrm{c} \text {,avg }}$ on laser power is presented in Fig. 7. A trend line is added to the data as a third degree polynomial fit. It can be seen that both $w_{\mathrm{c} \text {,max }}$ and $w_{\mathrm{c} \text {,avg }}$ increase with laser power, for low laser powers, and then decrease linearly for laser powers above $80 \mathrm{~W}$, with the values at $80 \mathrm{~W}$ still being significantly larger than at $0 \mathrm{~W}$. This suggests that the optimal laser power for the machining parameters used is outside the tested range, above $160 \mathrm{~W}$.

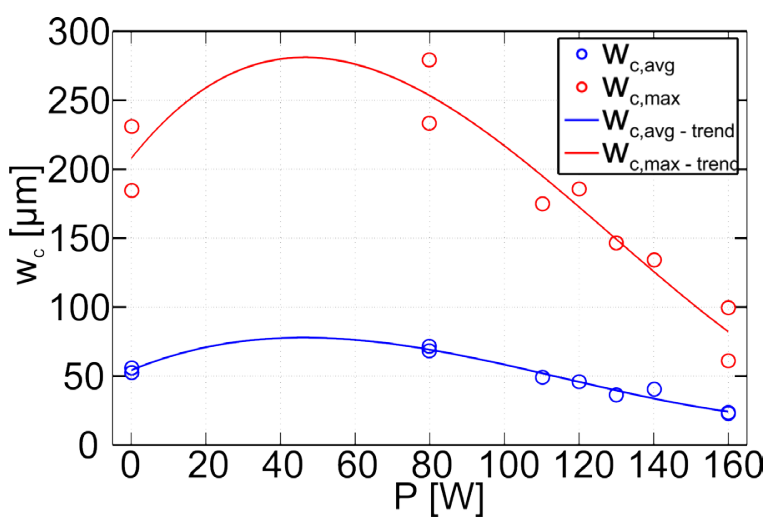

Fig. 7. Edge chipping for different laser powers
It can be seen in Fig. 7 that the benefits of laser assistance are only achieved with laser powers exceeding $110 \mathrm{~W}$, where both $w_{\mathrm{c} \text {, max }}$ and $w_{\mathrm{c} \text {,avg }}$ are reduced, compared to those, achieved by conventional milling. This suggests that the glassy transition of the Bi-rich intergranular phase plays an important role in interior edge chipping as well as in the previously discussed surface roughness. Similarly, for the case of $\mathrm{Si}_{3} \mathrm{~N}_{4}$, Yang et al. [9] report that there are two factors, contributing to edge toughness. Firstly, edge chipping is reduced due to reduction in cutting forces in LAMill and secondly, while increasing laser power so to heat the material above the glassy transition temperature, the edge toughening mechanism takes place, further reducing edge chipping.

\subsection{Optimal Level of Laser Power}

This study showed that positive effects on the machinability of $\mathrm{ZnO}$ ceramics in terms of reduction of interior edge chipping and improved machined surface quality can be achieved with laser assistance by adjusting laser power. At a laser power of $120 \mathrm{~W}, R_{\mathrm{a}}$ and $R_{\mathrm{z}}$ were reduced by $37 \%$ and $46 \%$, respectively, compared to conventional milling, and a 4.5- and 7-fold reduction in the difference between the highest and lowest measured values was observed for $R_{\mathrm{a}}$ and $R_{\mathrm{z}}$, respectively at this laser power. The highest reduction of edge chipping was obtained at the highest laser power used, $160 \mathrm{~W}$, where the average and maximum chipping widths were reduced by $55 \%$ and $60 \%$, respectively. However, using this level of laser power resulted in cracks in the workpiece due to thermal shock, as shown in Fig. 8. The stresses, as a consequence of excessive temperature gradient are causing this problem. Based on this, the minimum power above the glassy transition point is considered as the most reliable choice by the authors (i.e. $120 \mathrm{~W}$ ). By using a laser power of $120 \mathrm{~W}$, the average and maximum chipping widths were reduced by $15 \%$ and $17 \%$, respectively.

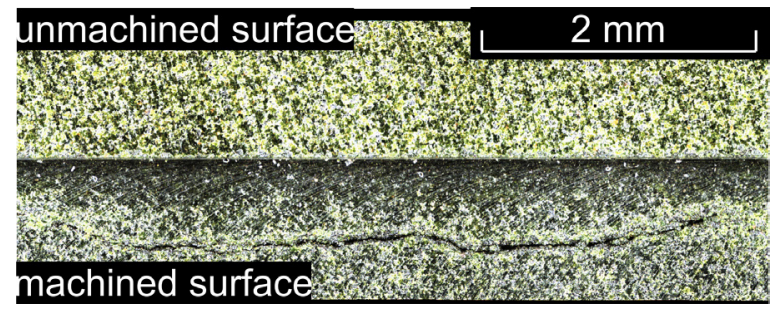

Fig. 8. Thermal crack, formed when using a laser power of $160 \mathrm{~W}$ 


\section{CONCLUSIONS}

The paper contributes to an advanced understanding of laser assistance and represents a pioneering work in the field of LAMill of $\mathrm{ZnO}$ ceramics. Conventional milling and LAMill experiments, using various levels of laser power, were conducted to determine the effect of laser power on the machined surface integrity. The key findings of this research are summarized as follows.

- Edge chipping is the main factor, reducing the machinability of $\mathrm{ZnO}$ ceramics. Laser assistance can improve the machinability of $\mathrm{ZnO}$ ceramics by reducing edge chipping and improving surface roughness. For the machining parameters used, an optimal level of laser power exists, where the highest improvement in machinability was achieved.

- At the optimal level of laser power of $120 \mathrm{~W}$, $R_{\mathrm{a}}$ and $R_{\mathrm{z}}$ were reduced by $37 \%$ and $46 \%$, respectively.

- $\quad$ By using a laser power of $120 \mathrm{~W}$, the average and maximum chipping widths were reduced by $15 \%$ and $17 \%$, respectively. Higher reductions in edge chipping were achieved at higher levels of laser power, but cracks due to thermal shock started to appear on the machined surface.

Although the novel approach of LAMill applied in this study showed an improvement in the machinability of this material, many areas are yet to be researched to fully understand and implement LAMill in $\mathrm{ZnO}$ ceramic part production. As concluded previously, edge chipping is considered the main factor reducing the machinability of $\mathrm{ZnO}$ ceramics and LAMill of this material is limited by thermal shock. Therefore, a thermal model that can reliably predict temperatures near the edges of the workpiece after laser heating is crucial for further studies of LAMill of this material. Furthermore, the mechanisms that result in the improvement of surface integrity, while machining $\mathrm{ZnO}$ at high temperatures have to be researched to master LAMill of $\mathrm{ZnO}$.

\section{ACKNOWLEDGEMENTS}

The authors would like to thank the Slovenian Research Agency (ARRS) for their financial support through the P2-0266 Research Program and prof. dr. Slavko Bernik from the Department for Nanostructured materials at the Jožef Stefan Institute for his support with knowledge in the field of $\mathrm{ZnO}$ ceramics.

\section{REFERENCES}

[1] Ng, S.J., Le, D.T., Tucker, S.R., Zhang, G. (1996). Control of Machining Induced Edge Chipping on Glass Ceramics. Institute of System Research, University of Mariland, College Park.

[2] Shih, A.J., Denkena, B., Grove, T., Curry, D., Hocheng, H., Tsai, H.-Y., Ohmori, H., Katahira, K., Pei, Z.J. (2018). Fixed abrasive machining of non-metallic materials. CIRP Annals, vol. 67, no. 2, p. 767-790, DOl:/10.1016/j.cirp.2018.05.010.

[3] Wang, J., Zhang, J., Feng, P., Guo, P. (2018). Damage formation and suppression in rotary ultrasonic machining of hard and brittle materials: A critical review. Ceramics International, vol. 44, no. 2, p. 1227-1239, Dol:10.1016/j.ceramint.2017.10.050.

[4] Guerrini, G., Fortunato, A., Melkote, S.N., Ascari, A., Lutey, A.H.A. (2018). Hybrid laser assisted machining: A new manufacturing technology for ceramic components. Procedia CIRP, vol. 74, p. 761-764, Dol:10.1016/j.procir.2018.08.015.

[5] Zhang, X., Deng, Z., Ren, Y., Chen, G., Liu, W., Zhang, G. (2015). Laser-induced deterioration grinding of zirconium oxide ( $\mathrm{ZrO} 2)$ - generation of layer patterns and performance evaluation. Strojniški vestnik - Journal of Mechanical Engineering, vol. 61, no. 12, p. 689-697, D0I:10.5545/sv-jme.2015.2794.

[6] Pachaury, Y., Tandon, P. (2017). An overview of electric discharge machining of ceramics and ceramic based composites. Journal of Manufacturing Processes, vol. 25, p. 369-390, DOI:10.1016/J.jmapro.2016.12.010.

[7] Samant, A.N., Dahotre, N.B. (2009). Laser machining of structural ceramics-a review. Journal of the European Ceramic Society, vol. 29, no. 6, p. 969-993, D0l:10.1016/j. jeurceramsoc.2008.11.010.

[8] Sun, S., Brandt, M., Dargusch, M.S. (2010). Thermally enhanced machining of hard-to-machine materials-a review. International Journal of Machine Tools and Manufacture, vol. 50, no. 8, p. 663-680, D0I:10.1016/j.jimachtools.2010.04.008.

[9] Yang, B., Shen, X., Lei, S. (2009). Mechanisms of edge chipping in laser-assisted milling of silicon nitride ceramics. International Journal of Machine Tools and Manufacture, vol. 49, no. 3-4, p. 344-350, Dol:10.1016/j. ijmachtools.2008.09.006.

[10] Lei, S., Shin, Y.C., Incropera, F.P. (2001). Experimental investigation of thermo-mechanical characteristics in laserassisted machining of silicon nitride ceramics. Journal of Manufacturing Science and Engineering - Transactions of the ASME, vol. 123, no. 4, p. 639-646, Dol:10.1115/1.1380382.

[11] Tian, Y.G., Shin, Y.C. (2006). Thermal modeling for laserassisted machining of silicon nitride ceramics with complex features. Journal of Manufacturing Science and Engineering - Transactions of the ASME, vol. 128, no. 2, p. 425-434, DOI:10.1115/1.2162906.

[12] Pfefferkorn, F.E., Shin, Y.C., Tian, Y.G., Incropera, F.P. (2004). Laser-assisted machining of magnesia-partially-stabilized zirconia. Journal of Manufacturing Science and Engineering - Transactions of the ASME, vol. 126, no. 1, p. 42-51, DOI:10.1115/1.1644542.

[13] Tian, Y.G., Wu, B.X., Anderson, M., Shin, Y.C. (2008). Laser-assisted milling of silicon nitride ceramics and inconel 718. Journal of Manufacturing Science and 
Engineering - Transactions of the ASME, vol. 130, no. 3, DOl:10.1115/1.2927447.

[14] Bernik, S. (2017). Influence of granulate and pressure on green compacts and the current-voltage characteristics of sintered zno-based varistor ceramics. Journal of Microelectronics, Electronic Components and Materials, vol. 47, no. 3, p. 171-177.

[15] Roy, T.K. (2015). Assessing hardness and fracture toughness in sintered zinc oxide ceramics through indentation technique. Materials Science and Engineering: A, vol. 640, p. 267-274, DOI:10.1016/j.msea.2015.05.107.
[16] Ferraris, E., Vleugels, J., Guo, Y., Bourell, D., Kruth, J.P., Lauwers, B. (2016). Shaping of engineering ceramics by electro, chemical and physical processes. CIRP Annals, vol. 65, no. 2, p. 761-784, D0l:10.1016/j.cirp.2016.06.001.

[17] Kim, Y. J., Hwang, S. J., Kim, H. S. (2006). Thermal Properties of Bi203-B203-Zn0 Glass System. Materials Science Forum, vol. 510-511, p. 578-581, D0I:10.4028/www.scientific.net/ MSF.510-511.578.

[18] Ohbuchi, Y., Matsuo, T., Sakat, M. (1995). Chipping in highprecision slot grinding of $\mathrm{Mn}-\mathrm{Zn}$ ferrite. CIRP Annals, vol. 44, no. 1, p. 273-277, D0l:10.1016/S0007-8506(07)62324-5. 